\title{
Feminismo y mujeres migrantes en Costa Rica. Articulaciones pendientes en torno al trabajo doméstico remunerado
}

Karina Fonseca Vindas

Servicio Jesuita para Migrantes Costa Rica, San José. Correo electrónico: karifonseca@gmail.com

Recibido: mayo de 2008 / Aceptado: junio de 2008

ESTE ARTÍCULO PROPONE UN ACERCAMIENTO CRÍTICO A LA SITUACIÓN QUE enfrentan miles de mujeres trabajadoras domésticas en Costa Rica, principalmente las difíciles condiciones laborales que deben soportar mujeres migrantes nicaragüenses al ser contratadas en casas de habitación costarricenses. Ellas son quienes sufren los mayores atropellos y suelen experimentar un grado más alto de desprotección respecto de las nacionales.

Las vivencias de las trabajadoras domésticas evidencian los serios conflictos que rodean los esfuerzos orientados a la concreción de articulaciones teóricas y prácticas entre la condición de ser mujer, la clase social a la que se pertenezca y la nacionalidad. Para efectos de este trabajo, cobra especial interés además, la necesidad de reconocer la labor doméstica como una ocupación homologable a los otros trabajos contemplados en la legislación laboral de Costa Rica, así como la urgencia de que las reivindicaciones asociadas al trabajo doméstico remunerado adquieran mayor protagonismo en las agendas derivadas de la conciencia feminista dominante.

Si bien las organizaciones de mujeres han abierto significativas rutas hacia la reducción de la desigualdad histórica entre hombres y mujeres, es indispensable reconocer que las mujeres no son un grupo homogéneo, sino que experimentan tensiones y contradicciones a lo interno de su condición, que vuelve sumamente compleja la justificada búsqueda de una real equidad de género.

Palabras clave: Trabajo doméstico remunerado / mujeres migrantes / feminismo / ámbito público / ámbito privado / legislación laboral / equidad de género 


\section{Introducción}

En las últimas décadas se ha dado un desencadenamiento paulatino de importantes logros para las mujeres en Costa Rica. La mayoría se asocia a cambios de orden legislativo vinculados a la protección de la integridad física y emocional, de incremento en la participación política, educacional y de inserción en ocupaciones remuneradas fuera del hogar. A mediados de la década de los 90 en Costa Rica se ratifica la Convención de Belem do Pará (1995) y se aprueban diversas leyes sobre hostigamiento sexual, violencia doméstica, pensiones alimentarias, uniones de hecho, niñez y adolescencia, explotación sexual comercial, derechos sexuales y reproductivos, entre otros temas relativos a la ampliación de derechos de las mujeres y de otras poblaciones particulares (Sagot, 2006:280).

Además, Costa Rica se ha convertido en uno de los países a nivel mundial con más alta participación de mujeres en el Congreso, a pesar de que aún es insuficiente respecto de la ley vigente. ${ }^{1}$ Notables también han sido los avances en la esperanza de vida de las mujeres (81,6 años y 76,6 en los hombres) (PNUD, 2007); en el incremento en la participación neta en el empleo remunerado en los últimos años y en el hecho de que cerca del 60 por ciento de los estudiantes graduados en las universidades estatales son mujeres, siendo además la población femenina total la que cuenta con un número mayor de años de estudio promedio, en relación con los hombres.

Los efectos positivos que tales avances tienen sobre las poblaciones femeninas en Costa Rica son innegables y ubican al país como pionero en América Latina en lo que respecta a la promulgación de leyes dirigidas hacia la igualdad entre mujeres y hombres (PNUD, 2007). El justo activismo de las mujeres se ha empeñado en consolidar modificaciones de orden jurídico, tanto para regular la violencia de género, como para ampliar la participación femenina en los espacios reservados históricamente para los hombres, siendo una de las preocupaciones principales el tema laboral.

No obstante, el acceso a empleos en igualdad de condiciones sigue planteando enormes desafíos a pesar del incremento que se registra en la ocupación femenina remunerada. La desatención histórica de la que han sido objeto las mujeres por parte de las políticas gubernamentales se materializa en la notoria inequidad que prevalece en las formas de inserción, el subempleo, el acoso y los bajos salarios, que son sólo algunos ejemplos que muestran que el camino está a medio andar. Además, la obtención de empleos "puerta a afuera" por parte de las mujeres favorece el recrudecimiento de materias irresueltas en los espacios domésticos, específicamente la responsabilidad -aún en manos femeninas- de la ejecución de los deberes propios de dicho ámbito.

La solución de algunas de las tensiones más importantes entre hombres y mujeres no se logra únicamente con el aumento de la participación en la esfera pública de determinados sectores de mujeres, sino también pasa por el reconocimiento masculino de que el trabajo en el hogar sigue siendo una asignatura pendiente cada día, que tiene un valor, que debe ser compartido y que si existe una persona externa contratada para realizarlo, él es corresponsable del ofrecimiento de un trato justo y digno para quien lo desempeñe. 
Por otra parte, una arista poco tematizada en las agendas reivindicativas de género son las desigualdades que existen (jy aumentan?) entre ciertos grupos de mujeres respecto de otros, sobre todo porque las formas de contratación que prevalecen en el trabajo doméstico evidencian que aún estamos lejos de resolver prácticas subordinantes hacia sectores femeninos que se han quedado fuera de muchas de las transformaciones sociales, económicas y culturales planteadas desde el feminismo.

Las hondas diferencias que se establecen entre mujeres con oportunidades de desarrollo académico o profesional, visibilidad pública y acumulación de riqueza y las que no tienen esas posibilidades, desnudan las contradicciones internas que persisten en los debates de género. La lucha por la equidad, la solidaridad "intra-género" y las mujeres atrincheradas en un frente común son nociones que merecen formas alternativas de abordaje y autocrítica. ${ }^{2}$ En este contexto, se vuelve pertinente alentar discusiones que confronten el encuadre dominante sobre las luchas por la equidad de género que han prevalecido en Costa Rica, que sirvan a la vez para dejar al descubierto varias materias inconclusas sobre los roles que desempeñan las mujeres y los hombres, las relaciones de poder, la subordinación y la legitimización del orden patriarcal como elementos que cobran relevancia al lidiar con las formas habituales de comprender el trabajo doméstico remunerado.

Varias interrogantes confluyen y tratan de ser articuladas a lo largo de las páginas siguientes: ¿Por qué ha sido incipiente la participación de grupos feministas de capas medias en modificaciones de las condiciones laborales de los empleos "menos calificados" para mujeres?; ¿cuáles elementos mitigan la limitada incorporación de los hombres en las responsabilidades dentro del hogar?; ¿podríamos hablar de prácticas subordinantes de unas mujeres hacia otras mujeres, especialmente en detrimento de las migrantes?; ¿́por qué podría pensarse que son insuficientes las transformaciones ideológicas en los roles de género?

\section{Feminismo, ámbito privado y contradicciones}

Como es sabido, en muchas de las argumentaciones más prominentes sobre equidad de género uno de los hilos articuladores o desencadenantes clave ha sido la dicotómica relación entre los ámbitos público y privado. Un sinnúmero de elementos están profundamente arraigados a los debates sobre estas dos esferas que evidentemente tienen su origen en la relegación al plano doméstico que millones de mujeres a lo largo de la historia han sufrido y siguen sufriendo.

Como bien señala Moller Okin (en Sagot, 2006), a pesar de que se han concretados cambios, sobre todo en las sociedades occidentales, persisten concepciones ancestrales que se remontan a Aristóteles, cuya teoría de la justicia confinaba a las mujeres a la esfera del hogar, un lugar ocupado por personas que no eran iguales a los hombres libres, aquellos que podían participar activamente en la justicia política. De hecho toda la teoría política occidental y consecuentemente la estructura de las instituciones sociales ha estado influida por estas concepciones que consideran a la mitad de la humanidad -o la cuasi-humanidad, es decir a las mujeres- como encargadas de áreas de la vida definidas como fuera del ámbito de la justicia. 
Lo cierto entonces es que en todas las discusiones sobre el hogar y la esfera privada, uno de los elementos centrales en los movimientos feministas, como bien afirma la investigadora social Hildete Pereira, ha sido el de intentar promover la igualdad entre los sexos y crear una sociedad donde la división sexual del trabajo sea abolida y donde los hombres consagren una parte de su tiempo a los quehaceres domésticos en igualdad de condiciones con las mujeres, quienes podrían, por fin, participar en la vida política y social (Pereira, 1993).

Lamentablemente en la mayoría de los núcleos familiares dicha consagración o compromiso hacia el trabajo hogareño compartido no es una realidad. Es a la base de esta no apropiación masculina de las obligaciones domésticas que se pone de manifiesto uno de los aspectos más contradictorios en el trabajo pro equidad de género: la indispensable supresión del trabajo doméstico concebido como una labor netamente femenina. Como apunta Pereira:

...el servicio doméstico remunerado tiene efectos nocivos para las relaciones familiares. La empleada doméstica es como un amortiguador entre el esposo y la esposa que impide que explote la contradicción de quién tiene que hacer los quehaceres domésticos, para los cuales la han empleado. Es precisamente esa contradicción la que ha dado origen al movimiento feminista en los países donde la empleada doméstica prácticamente ha desaparecido (1993:230).

De esta manera, parte de los logros obtenidos en el marco de la proclamada liberación femenina $^{3}$, no son beneficios que hayan llegado producto de una justa división en los quehaceres del hogar y el cuido de los hijos, o mejor aún, por el declive del orden patriarcal que se impone en casi todas las esferas públicas y privadas. El aumento en el acceso a ocupaciones externas para mujeres que buscan "superarse", pero también para aquellas que asumen la lucha diaria por sobrevivir, ha sido posible -mayoritariamente- porque abuelas, tías, hermanas, vecinas o trabajadoras domésticas han minimizado los eventuales conflictos que desencadenan la ausencia femenina en el hogar.

En el caso costarricense, ante la afluencia de personas migrantes, sobre todo nicaragüenses, la posibilidad de contratar mano de obra barata para suplir el rol tradicional femenino en las familias, ha ido entorpeciendo y retardando, aún más, la participación masculina en los espacios domésticos y a la vez ha aplacado el disgusto, frustración y dobles jornadas de muchas mujeres que ahora forman parte del mercado laboral externo.

En este sentido, diferentes estudios referidos a la feminización de las migraciones dan cuenta de que la persistencia de un orden patriarcal en la división social del trabajo y la asignación de roles según sexo deben mucha de su vigencia a la preeminencia de un modelo económico que resulta incompatible con la equidad y una justa distribución de la riqueza en los países subdesarrollados como es el caso de Costa Rica y el resto de los países centroamericanos. $\mathrm{Al}$ respecto sostiene Gloria Moreno-Fontes:

...los procesos económicos relacionados con la liberalización del comercio y los movimientos de capital, así como la búsqueda de una rentabilidad cada vez mayor del capital y la reorientación de las políticas para 
responder a las exigencias del mercado, han repercutido poderosamente en los mercados laborales mundiales, donde se contrata cada vez más a trabajadores migrantes no documentados por constituir una fuerza laboral barata y flexible y porque están dispuestos a aceptar condiciones de trabajo y empleo que los trabajadores autóctonos rechazan. De hecho, la precarización del empleo menos remunerado y su carácter cada vez más informal, así como la eliminación o relajación de las normas y reglamentaciones gubernamentales de los mercados laborales, han hecho principalmente que numerosos empleadores contrataran a trabajadores migrantes no documentados y, en muchos casos, preferentemente a mujeres (2002:48).

Siguiendo a la misma autora, al analizar los sectores donde existe una demanda de mano de obra femenina migrante -como sucede en Costa Rica- se observa una prolongación del papel que se asigna tradicionalmente a las mujeres y un fortalecimiento de los estereotipos femeninos. Ello, aunado a las contradicciones presentes en las iniciativas de las agrupaciones feministas interpeladas discursivamente por el trabajo doméstico y su visibilización, pero que con frecuencia deben lidiar con la ambivalencia entre su propia dinámica familiar y la retórica reivindicativa que sostienen, sirve la mesa para la discusión sobre equidad de género y las limitaciones que aún se registran.

El trabajo doméstico sigue siendo un asunto de mujeres, la incorporación de los hombres a las labores del hogar es aún insuficiente. Las mujeres asumen mayoritariamente la figura de "patrona" frente a las mujeres que ahora "las suceden en sus tradicionales obligaciones". ¿Cómo entonces manejar la enorme contradicción y el fracaso, tanto de un modelo socioeconómico injusto, de una equidad de género que beneficia a sectores femeninos muy específicos y del predominio de un orden patriarcal que continúa construyendo legitimidad para el tan discutido binomio "mujer/hogar"?

La esfera privada, como un eventual espacio de atropello, marginación y limitaciones para las mujeres, no es una historia acabada para amplios sectores femeninos de las sociedades actuales. No es tampoco un ámbito que queda vaciado de contenido o que pierde relevancia, todo lo contrario, adquiere nuevas tonalidades, múltiples significados y preocupantes expresiones de vulnerabilidad femenina, no para la mujer que trabaja como funcionaria de un banco o una ONG, para citar un par de ejemplos entre los múltiples posibles. Preocupa aquella "otra" que asume ahora los roles de cuido de niños, limpieza, cocina y un gran número de tareas domésticas que no se detienen dentro del hogar y que aún así, son precariamente reconocidas tanto por las legislaciones locales e internacionales, como por el ideario prevaleciente de subvaloración a las labores que se ejecutan dentro de una vivienda.

La homologación del trabajo doméstico a cualquier otro trabajo, no es un logro que esté tan próximo, la inacción de los Estados, la falta de priorización del tema, y la presión que ejercen sectores empresariales y otros que pudiesen sentirse afectados y que entorpecen el curso de transformaciones significativas, van en detrimento de las condiciones laborales de miles de mujeres en América Latina y otras regiones del mundo. 
En el año 2006, durante encuentros de distintos sectores para discutir las modificaciones a la actual ley migratoria en Costa Rica, una de las preocupaciones que manifestaron varias mujeres profesionales cercanas al tema migratorio era la inminente irrupción en "su espacio privado" que significaría las inspecciones que la Dirección General de Migración y Extranjería de Costa Rica y el Ministerio de Trabajo pueden llevar a cabo en casas de habitación para corroborar la situación laboral de las trabajadoras domésticas. Alusiones como: "Es mi casa cómo se van a meter ahí, mi hogar no es una empresa", sintetizan una de las tensiones irresueltas entre feminismo y derechos laborales de las mujeres trabajadoras domésticas.

Las mujeres trabajadoras domésticas merecen que se acabe con la errónea noción de que la casa de habitación de sus patronos/as es un espacio privado. Una de las principales banderas de las feministas alrededor del mundo ha sido la de denunciar los grandes abusos que históricamente millones de mujeres han sufrido y siguen sufriendo en el denominado "ámbito privado". Razón por la que representa un enorme retroceso darse cuenta de que mujeres insertas ahora en espacios laborales externos, otrora reservados para hombres, secunden las nuevas y viejas formas de subordinación que prevalecen en los espacios domésticos.

Miles de viviendas en Costa Rica y muchas otras en distintos países, son ahora el espacio público de muchas mujeres trabajadoras. Se podría hablar incluso de nuevas formas alternativas a las nociones dominantes-de liberación femenina, una modalidad de liberación muchas veces incomprendida por los movimientos feministas y que se propone como un llamado de atención para revisar críticamente los enfoques investigativos sobre el trabajo doméstico, algunos de los cuales se instalan de forma inamovible en perspectivas cuya peculiaridad es la revictimización. Ello se nota más en las referencias sobre emigración femenina. Laura Agustín señala, por ejemplo, que:

es notable que [en] el año 2001 se siga considerando a las mujeres como empujadas, obligadas, coaccionadas o forzadas, cuando salen de sus países por la misma razón que los hombres: para progresar mediante el trabajo. Pero tan arraigada está la idea de la mujer como parte esencial de la casa, y hasta como la encarnación misma de la casa, que se les niega sistemáticamente el protagonismo que implica la decisión de emigrar. Se considera que los problemas dañarán irreparablemente a las mujeres que son evaluadas, junto a los niños, mientras que se espera que los hombres enfrenten y superen los problemas de manera rutinaria (Agustín, 2002; citada por Balbuena, 2003).

El aporte de la autora muestra el encuadre tan limitado que algunas veces impera en torno a la idea de "la liberación femenina", pues lo que para unas mujeres puede significar desarraigo y subordinación para otras puede ser una ventana al progreso, una estrategia para tomar control de sus vidas y posibilitar la sobrevivencia de sus familias. Sin embargo, tampoco se debe entender lo anterior como una aceptación de las empobrecidas condiciones de vida de los países de origen que impide que sus habitantes puedan quedarse en forma digna, mucho menos aplaudir las precarias formas de inserción laboral y las violaciones de derechos que 
se cometen en los países de arribo como mecanismos facilitadores y promotores de una modalidad de superación femenina.

Lo que sí interesa es dar cuenta de que el espacio doméstico de una mujer puede ser el espacio público o externo de otra y que la emigración, como un fenómeno en extremo complejo, posibilita perspectivas alternativas para problematizar en torno a los distintos roles ocupados por las mujeres, aunque ello no implique que se pueda abandonar el orden patriarcal que articula, aún con mucha fuerza, las dinámicas en la mayoría de las sociedades contemporáneas.

\title{
3. Trabajo doméstico remunerado en Costa Rica: logros y asignaturas pendientes
}

\begin{abstract}
Las líderes de las trabajadoras domésticas han desconfiado profundamente de quienes deberían ser sus aliados naturales: mujeres en organizaciones profesionales y grupos feministas. De las primeras desconfían porque sus esfuerzos por ayudarlas en muchos casos se han convertido en proyectos para proporcionar a las mujeres de clase media y alta sirvientas más eficientes. Sobre los segundos se plantean dudas por la ambivalencia de algunas feministas, que no desean alterar la actual relación patrona/ empleada, de la cual depende su propia libertad para llevar a cabo su trabajo y actividades. Tampoco grupos feministas, salvo raras excepciones, han asumido la causa de las trabajadoras domésticas (Chaney y García, 1993:14).
\end{abstract}

El trabajo doméstico remunerado es la principal fuente de empleo para las mujeres en América Latina y el Caribe y evidentemente las mujeres más pobres son las que de manera mayoritaria se incorporan a este tipo de ocupación, sufriendo explotación laboral, desprotección jurídica, exclusión y discriminación. La ausencia de datos confiables sobre el número de mujeres ocupadas en dichas tareas en Costa Rica es una gran limitante. Algunas estimaciones apuntan a 80 mil o más y más del 40 por ciento, se calcula, son mujeres migrantes nicaragüenses. (ASTRADOMES, 2004:23)

Una encuesta realizada por $\operatorname{ASTRADOMES}^{4}$ permitió distinguir tres tipos de jornadas de trabajo: por un día en una sola casa, por horas en varias casas y fija con dormida. Como consecuencia del desarraigo de su lugar de origen, el comportamiento de la población migrante en cuanto a forma de trabajo se refiere, hace que prevalezca una mayor concentración en la forma fija con dormida, esto es, de cada 100 trabajadoras inmigrantes, 56 se desempeñan en dicha forma de trabajo, de las cuales 52 son nicaragüenses (ASTRADOMES, 2004:25). A esto habría que sumarle que la necesidad de vivir con la familia contratante tiene que ver también con la incapacidad de costear un lugar propio por el bajo salario recibido y por la presión que suelen ejercer muchos patrones, pues saben que contar con la trabajadora doméstica en el hogar de forma permanente significa una disponibilidad laboral mayor y a veces irrestricta en jornadas y tipo de tareas asignadas.

Por otra parte, se ha afirmado que la delegación de trabajo doméstico a terceras personas en condición remunerada es sólo posible para una minoría de empleadores costarricenses, 
pues para sostener una empleada doméstica, se requiere ganar por lo menos dos veces el sueldo mínimo, a no ser que: no se le pague; se le pague en especies equivalentes a montos inferiores al salario mínimo; se le pague menos de lo que corresponde por ley; se arregle el pago a través del intercambio de favores; o se contrate por horas y para tareas puntuales (Lerussi, 2008:60).

Sin embargo, más que el carácter excepcional o reducido para la contratación del servicio doméstico, es fácilmente presumible que lo que impera es el auge de formas extendidas de subcontratación laboral, remuneraciones exiguas y evasión sistemática de las responsabilidades patronales (indemnizaciones, seguridad social, etc.). En la actualidad, el empleo doméstico remunerado representa en Costa Rica alrededor de un 16\% de la población ocupada femenina, superado únicamente por una categoría a la que se denomina "comercio mayor y menor" ${ }^{5}$ con 18\% y por encima de una ocupación tradicionalmente femenina como es la docencia con 10,5\% del total de los trabajos desempeñados por mujeres (INAMU, 2008).

Lo cierto entonces es que sin desmerecer la significativa y creciente participación de las mujeres en distintos espacios laborales extra-domésticos, se debe insistir en que parte importante de estos accesos se han ido gestando a costa de grupos femeninos en mayor grado de vulnerabilidad que asumen la carga de las labores domésticas en miles de hogares costarricenses. El imaginario que rodea el trabajo doméstico remunerado y la comprensión del mismo como una tarea desvalorizada e inherente a las mujeres, ha provocado que no sea reconocido en los mismos términos que el resto de las ocupaciones amparadas en el marco jurídico costarricense.

Aunque aquí no se pretende ahondar en el engranaje ideológico-histórico que explica el débil marco legal que prevalece en Costa Rica para las personas ocupadas como trabajadoras domésticas, merece la pena hacer un breve recuento que muestre cómo la legislación laboral y otras asociadas han heredado muy poco de los debates contemporáneos en materia de equidad de género. El espacio privado y las labores domésticas siguen ocupando un lugar marginal y la legislación vigente en esta materia no está a tono con las demandas y logros en otras esferas que las mujeres han alcanzado en las últimas décadas.

En el año 1943 se aprueba el Código de Trabajo, dentro del cual se incluye el capítulo VIII: Del trabajo de los servidores domésticos (art. 101 a 112, vigente hasta la fecha con modificaciones). En el artículo 101 se define a los/las trabajadores/as domésticos/as como "aquellos(as) que se dedican en forma habitual y continua a labores de aseo, cocina, asistencia, y demás propias de un hogar, residencia o habitación particulares, que no importen lucro o negocio para el(la) patrono(a)". A éste le sigue toda la serie de artículos referidos a los derechos y las obligaciones por parte del/la trabajador/a y del/la empleador/a. A su vez, respecto al contrato de trabajo, en el inciso b) artículo 22 , se indica que "el contrato de trabajo podrá ser verbal cuando se refiera al servicio doméstico”, característica que perdura hasta la actualidad y que agrava aún más la situación de discriminación en la que se encuentran las trabajadoras domésticas, dejando fuera el control de las autoridades administrativas (Agenda Política de las Mujeres et al. 2003 citado por Lerussi, 2008:5). 
Casi 20 años después de la entrada en vigencia de dicho instrumento jurídico, nace en el año 1962 la Asociación de Servidoras Domésticas de Costa Rica, como un primer esfuerzo organizativo de las trabajadoras domésticas en Costa Rica y con el apoyo del ala sindical de sectores de la Iglesia Católica. Durante la década que estuvo activa, se planteó como objetivo reformar el Código de Trabajo en el capítulo del servicio doméstico, produciéndose las siguientes modificaciones legales: la regulación de la jornada laboral a 12 horas ordinarias, anteriormente la jornada laboral era ilimitada; las limitaciones a jornadas laborales en caso de menores de 18 años y desde los 12 años de edad; el establecimiento del derecho a feriados y descanso semanal de media jornada y el derecho a 15 días de vacaciones anuales (ASTRADOMES, 2004).

Estas reformas se mantuvieron hasta la década de los 90. En 1991 nace ASTRADOMES, que tuvo desde sus inicios como reivindicación central la equiparación de la normativa que regula el trabajo doméstico con cualquier otro trabajo contemplado en el Código de Trabajo y la eliminación de las discriminaciones presentes en la legislación. A su vez, lleva desde entonces una fuerte labor de sensibilización y difusión de información en materia de derechos de las trabajadoras domésticas, dirigida a ellas y a los/las empleadores/as (Lerussi, 2008).

Además, una de las principales preocupaciones de ASTRADOMES ha sido lograr que las trabajadoras del gremio se perciban como tales y no como sirvientas o criadas y es desde ese esfuerzo de autoreconocimiento que se articula toda la lucha para que el trabajo doméstico remunerado sea equiparado con cualquier otro trabajo que regule el Código de Trabajo (ASTRADOMES, 2004). Quizás quien mejor reseña la trayectoria de ASTRADOMES y sus múltiples batallas en materia de reformas legislativa es Romina Lerussi en su reciente estudio sobre trabajo doméstico en Costa Rica (2008), que a continuación se detalla:

Desde 1994 y de manera continua, ASTRADOMES, organizaciones de mujeres y feministas, INAMU (Instituto Nacional de las Mujeres), entre otros actores y actoras, vienen presionando a la Asamblea Legislativa por un cambio en las leyes; sin embargo han recibido escaso apoyo. Por ejemplo, en el voto $N^{\circ} 3150$-1994, la Sala Constitucional argumentó en relación a la discriminación referida a las trabajadoras domésticas, diciendo que el régimen de la jornada laboral de las mismas constituye un caso de excepción autorizado por la Constitución Política y, en consecuencia, no hay ninguna inconstitucionalidad con este extremo.

En el bienio 1995 - 1996, en la Asamblea Legislativa se discutió una reforma al artículo 104 del Código de Trabajo, que reducía la jornada de las trabajadoras domésticas a 9 horas diarias, incluyendo una hora de descanso, acumulables durante los primeros cinco días de la semana, y mantenía la posibilidad de una jornada extraordinaria de 4 horas diarias. Este proyecto fue vetado por el presidente de la República, José María Figueres Olsen (1994 - 1998) (RUIZ ARCE, J. y VARGAS MADRIGAL, O. F. 2001:13).El 24 de noviembre de 2005, se llevó adelante una acción de inconstitucionalidad por parte de ASTRADOMES en relación al art. 104, 
incisos c), d) y e) del Código Laboral que regula la jornada laboral, los días de descanso y los feriados. En marzo de 2007, la Sala Constitucional (resolución $N^{\circ} 3043$ - 07) dio lugar a una serie de puntos de dicha acción, llevando a un día completo el día de descanso (por lo general el domingo) y a día completo los feriados (en ambos casos, antes eran de sólo media jornada; Código Laboral, art. 104, punto dy e) y declarando inconstitucionales tres párrafos dentro del inciso c), referidos a: la posible división en fracciones de la jornada laboral que la extendería a 15 horas, la jornada de máximo doce horas para personas de entre 12 y 18 años y la eventual extensión de la jornada laboral a cuatro horas de carácter extraordinario (es decir, de 12 a 16 hs). (AGENDA POLÍTICA DE LAS MUJERES et al 2003) (Lerussi, 2008:58).

Sin embargo, a pesar del avance positivo que representó este fallo de la Sala Constitucional, emitido el 8 de marzo de 2007, día internacional de la mujer, la señora Rosita Acosta ${ }^{6}$ insiste en que los logros obtenidos fueron parciales, al no aprobarse una de las modificaciones fundamentales solicitadas, que es la equiparación de la jornada laboral de las trabajadoras domésticas a la del resto de trabajadores/as, es decir, llevar el horario diario de 12 horas a 8 horas. Falta también que las reformas logradas pasen a formar parte del documento oficial en materia laboral, es decir, el Código de Trabajo de Costa Rica.

Adicionalmente a todo este arduo proceso, existe una agenda paralela que atañe a casi la mitad de las trabajadoras domésticas y que tiene que ver con las difíciles condiciones que enfrentan las mujeres migrantes, que no sólo sufren la discriminación presente en la legislación laboral que rige en el país, sino que son víctimas de olvido reivindicativo del feminismo costarricense que aún es incipiente en el tema de mujeres migrantes y la política migratoria nacional. Claramente el tema migratorio ha permanecido muy desvinculado de las discusiones sobre equidad de género que se han articulado con mucha vehemencia en otros escenarios políticos, económicos y sociales.

\section{Mujeres nicaragüenses, ausentes en las agendas pro equidad de género}

"Ya te compré, ahora no te me podés ir". ${ }^{7}$ Ese fue el comentario que le hizo "una patrona" a la trabajadora doméstica que contrató al finalizar los engorrosos trámites para obtención del permiso laboral en la Dirección General de Migración y Extranjería de Costa Rica, cuyo costo estimado oscila entre los $\$ 200$ y $\$ 300 .{ }^{8}$ Y pareciera que no hay nada de exagerado y mucho menos de broma en la expresión, los permisos laborales para trabajadoras domésticas en Costa Rica son complicados de gestionar, "atan" a la persona a una determinada patrona o patrón (en el momento que se acaba la relación laboral se pierde el permiso) y se debe gestionar casi en su totalidad con extrema colaboración del contratante.

Tanto antes como después de obtener el permiso laboral, las mujeres migrantes sufren la amenaza latente y el temor fundamentado de que su patrón o patrona (es más frecuente que la figura contratante o de autoridad sea otra mujer), ante un disgusto "le eche Migración", lo que obliga a muchas de ellas a adoptar un estilo de vida de gran sumisión y miedos. Cientos de mujeres son explotadas, se les irrespetan sus derechos laborales (tanto en 
jornadas, funciones, paga, prestaciones y aguinaldo, etc.). Paradójicamente el salario de las trabajadoras domésticas no supera siquiera los $\$ 200$, siendo el más bajo entre todas las categorías salariales, a pesar de que debe cumplir la jornada laboral más extensa entre todos los trabajadores y trabajadoras mencionados en el Código de Trabajo costarricense, pues el horario puede alcanzar hasta doce horas diarias y no las ocho que estipula dicho instrumento jurídico para todos los demás trabajadores, y según el cual, después de ocho horas se pagarían horas extras, no así para las trabajadoras del hogar.

En buena teoría, el bajo salario de las trabajadoras domésticas se compensa con el salario en especie que se les otorga (hospedaje, alimentación), y debe ser contemplado en el pago de indemnizaciones y otras garantías laborales, pero tal responsabilidad patronal con frecuencia es irrespetada o sólo favorece a quienes viven de forma permanente en la vivienda donde son contratadas y no a quienes trabajan por horas o en una jornada diurna parcial o de día completo. Lo que sí parece imperar es la noción retrógrada e históricamente discutida por las agrupaciones feministas, según la cual el trabajo doméstico remunerado sufre las consecuencias de ser visto aún como una ocupación inherente a las mujeres, escaso de valor y fácil, lo que incide en que la remuneración sea baja y que con suma frecuencia escape a la protección y reconocimiento jurídico.

Quien diga que ya no existen formas manifiestas y solapadas de esclavitud en países con índices de desarrollo medianamente alentadores, debería prestar oídos a las desgarradoras historias que cuentan trabajadoras domésticas en Costa Rica. ${ }^{10}$ El propósito de este apartado no es desmerecer el trato hospitalario y la justa relación de intercambio que existen entre muchas mujeres trabajadoras domésticas y sus empleadores, pero sí poner énfasis en el hecho de que el irrespeto de derechos laborales, atropellos a la dignidad humana e incluso relaciones de servidumbre y explotación, son circunstancias que muchas mujeres siguen experimentando.

Las trabajadoras domésticas migrantes, especialmente nicaragüenses, son quienes deben sortear los mayores obstáculos para incorporarse laboralmente en Costa Rica. En primera instancia, existe una institucionalidad establecida que refuerza la discriminación hacia las mujeres migrantes que deseen acceder a empleos en Costa Rica, lo que resulta notable en el hecho de que uno de los tres únicos empleos para el que se están emitiendo permisos laborales en Costa Rica es la ocupación doméstica en casa de habitación, a menos que sea una profesional de "alto nivel", para lo cual se establecen algunas excepciones en la legislación vigente.

En otras palabras, una mujer extranjera con bachillerato concluido e incluso con estudios universitarios que desee optar por un empleo como oficinista, contadora, médica, dependiente de una tienda, entre otros, no puede hacerlo por la vía legal mediante la gestión de un permiso de trabajo, aun cuando su patrono esté en total disposición de apoyar en la engorrosa tramitología para la contratación. Las mujeres migrantes que deseen trabajar en Costa Rica deben conformarse con ser trabajadoras domésticas, casi independientemente de su calificación.

Los tres tipos de trabajo a los que de manera realista, según las disposiciones del Ministerio de Trabajo y de la Dirección General de Migración y Extranjería, pueden acceder las 
personas nicaragüenses, específicamente las pobres que viajan en busca de mejores condiciones de vida son: la agricultura, el sector agroindustrial y el doméstico. Más allá de esas opciones quedan vedadas otras posibilidades, a menos que el extranjero arribe a Costa Rica como inversionista o que sea un profesional amparado por compañías multinacionales. La justificación principal es que las autoridades del país temen el desplazamiento de la mano de obra costarricense.

Uno de los desafíos que se le presenta a los movimientos sociales preocupados por los sectores más vulnerables en los países expulsores y de acogida -incluyendo el trabajo de los colectivos feministas- es la acogida no sólo de las críticas y acciones sobre las relaciones históricamente desiguales entre hombres y mujeres, sino también el impacto que tienen en las mujeres las relaciones crecientemente desiguales entre quienes acumulan capital y quienes cada vez están más desprotegidos/as y más aún cómo incidir de forma consistente en las relaciones desiguales entre unas mujeres y otras.

No cabe duda de que el feminismo se encuentra frente a una gran encrucijada, claramente señalada por Hildete Pereira, que es la enorme "dificultad de articular la conciencia feminista y la condición de clase" (1993:228). En gran medida es un avance que las [trabajadoras] domésticas hablen tan claramente de su condición de clase social y de la fuerza que les da este planteamiento y que las militantes feministas consideren que, pese a la contradicción de clase, la solidaridad entre las mujeres es posible por el mero hecho de ser mujeres, aunque se trate de una solidaridad en proceso de construcción (Pereira, 1993:233). Es urgente crear condiciones más justas para las mujeres que se enfrentan a mayores niveles de desprotección, violencia e inequidad.

Las mujeres migrantes resumen muchas de las principales imágenes de discriminación por razón de género, sobre todo la hostilidad y malos tratos que con frecuencia enfrentan por parte de sus empleadoras/es, así como el no reconocimiento pleno de sus derechos por la ausencia de documentos que certifiquen su permanencia "legal" en los países que arriban y los débiles cambios ideológicos relativos a la subvaloración del trabajo que realizan.

Género, clase y nacionalidad son palabras sobre las que queda aún mucho por decir y hacer. La autocrítica y balance a lo interno de las representaciones feministas, la reconfiguración del espacio privado como escenario laboral de muchas mujeres (remuneradas o no) y las modificaciones legislativas de orden migratorio y laboral, representan luchas que ya se están dando y en el caso costarricense aún deben eludir muchas dificultades. Sobre todo porque el modelo económico dominante y el encuadre patriarcal que articulan gran parte de las relaciones interpersonales hoy día, se coloca a la base de muchísimo del trabajo que lideran importantes grupos que creen y aspiran por una bien entendida equidad de género. Una más inclusiva y más justa. 


\section{Notas}

1 En 1990 se aprueba en Costa Rica la Ley de Igualdad Real de la Mujer, cuyo artículo 5 habla de la obligación de los partidos de dotarse de mecanismos efectivos para nombrar un "número significativo de mujeres" en sus estructuras internas y en las papeletas electorales. Una primera formulación de dicha Ley, planteando un $40 \%$ de representación femenina, tuvo que ser retirada ante la fuerte resistencia encontrada en ese momento en la Asamblea Legislativa.

Posteriormente, se interpreta este "número significativo" como un 40\% mínimo, y así queda recogido en las reformas al Código Electoral del 10 de diciembre de 1996, pero aún los partido encontraron portillos para no hacerlo efectivo, colocando a las mujeres en puestos no elegibles y en las suplencias. En el período 1998-2002 el número de diputadas fue de sólo un $19.3 \%$ del total.

Una serie de resoluciones del TSE a lo largo de 1999 y 2000, obliga a poner el $40 \%$ de mujeres en puestos elegibles de acuerdo a los puestos que históricamente cada partido ha logrado, y tanto en listas de titulares como de suplentes. Aún así, en el último período 2002-2006, las 20 diputadas electas sólo representaron el 35\% del total. Sólo el Partido Acción Ciudadana acogió realmente esta recomendación e incluyó en sus estatutos la paridad. En el otro extremo, la bancada del Partido Libertario destaca por una total ausencia de mujeres, a pesar de contar con seis representantes. (Información tomada de la página web: www.nuevaligafeminista.org) Consultada: 11/04/08.

2 Esto sin la mínima intención de menoscabar los incansables esfuerzos y logros de los grupos feministas en la confrontación de "la violencia contra las mujeres [entendida] como un componente estructural de sistema de opresión de género" (Sagot, 2006:273). No cabe duda de que estamos siendo partícipes de una época en la que se producen profundas transformaciones en la búsqueda de un orden político que reconfigure la institucionalidad de los Estados y la creación de políticas públicas que mejoren las condiciones de vida de las mujeres.

3 Gran cantidad de los cuales sólo impactan a algunos sectores específicos de mujeres en las sociedades modernas.

$4 \quad$ Siglas de la Asociación de Trabajadoras Domésticas en Costa Rica.

5 La categoría "comercio mayor y menor" incluye a ambos sexos, así que vale la pena recalcar que el trabajo doméstico es la ocupación a la que se dedica la mayor cantidad de mujeres que habitan en Costa Rica.

6 Entrevista personal, Sra. Rosita Acosta, presidenta y fundadora de ASTRADOMES, quien laboró durante más de 30 años como trabajadora doméstica en casas de habitación. Fecha de entrevista: miércoles 30 de abril 2008. Lugar: Casa de ASTRADOMES, Curridabat, San José, Costa Rica.

7 La expresión "Ya te compré, ahora no te me podés ir", fue compartida por una mujer migrante nicaragüense a Evelyn Solís, funcionaria del Servicio Jesuita para Migrantes en Costa Rica, en el momento en que la primera concluyó la tramitación de un permiso laboral en el mes de mayo de 2008.

8 Los requisitos que se solicitan en la Dirección General de Migración y Extranjería son el pasaporte ordinario con visa de turista vigente para ingresar a Costa Rica, si no tiene el pasaporte debe solicitarlo en el Consulado de Nicaragua en Costa Rica (\$55) y visa de entrada a Costa Rica (\$20), hoja de delincuencia del país de origen debidamente consularizada y certificada ( $\$ 50$ aproximadamente), y certificado de nacimiento debidamente consularizado y certificado ( $\$ 50$ aproximadamente). Si se le aprueba el permiso debe cancelar $\$ 20$ por impuestos y confección de documentos (los montos indicados a lo largo de este artículo se presentan en moneda estadounidense). Estos gastos sin contemplar algunos asociados como: traslados, días laborales perdidos para realizar gestiones, contratación de abogado, y si debe viajar a Nicaragua para gestionar la visa de turista, se debe añadir a la lista de gastos: pasajes, alimentación y hospedaje (de requerirlo). En algunos casos los empleadores se comprometen tanto económicamente, como ofreciéndole otras facilidades para que la trabajadora pueda llevar a buen término los trámites, pero en la mayoría de los casos, los contratantes consideran que es muy complicado y que el permiso los fuerza a responsabilizarse formalmente de la trabajadora, por lo que obligan a su empleada a mantenerse laborando de manera irregular a pesar de que se exponen a multas y a la posible deportación de la persona migrante.

9 Es una expresión que se utiliza como amenaza y que indica que "el o la nacional" puede llamar al cuerpo policial adscrito a la Dirección General de Migración y Extranjería de Costa Rica, que tiene potestad para trasladar a personas "sospechosas" de mantenerse de forma irregular en el país al Centro de Detención, sea para iniciar la verificación de su estatus migratorio o bien para iniciar el proceso de deportación a su país de origen.

10 Para acceder a historias documentadas al respecto se puede consultar Sandoval (2000). 


\section{Referencias bibliográficas}

AGUSTÍN, L. (2002) "Cuestionar el concepto de lugar: La migración es algo más que una pérdida”. En: Desarrollo, lugar, política y justicia. Las mujeres frente a la globalización. Roma. En: Feminización de las migraciones: del espacio reproductivo nacional a lo reproductivo internacional. (Balbuena, P.) Disponible en: http://guiagenero.mzc.org. es/GuiaGeneroCache/Pagina_ConstrGenero_000086.html\#globalizacionConsultado: 01/04/08.

ASOCIACIÓN DE TRABAJADORAS DOMÉSTICAS DE COSTA RICA (ASTRADOMES) (2004). Humanizando el trabajo doméstico: hacer visible lo invisible. La realidad de las trabajadoras del hogar en América Latina y El Caribe. San José: ASTRADOMES. Confederación Latinoamericana y del Caribe de Trabajadoras del Hogar (CONLACTRAHO).

CHANEY, E. \& GARCIA, M. (1993) "Introducción. Un nuevo campo de investigación y de acción". En: Muchacha / cachifa / criada / empleada / empregadinha / sirvienta / y... más nada. Trabajadoras domésticas en América Latina y El Caribe. Caracas: Nueva Sociedad.

INSTITUTO NACIONAL DE LAS MUJERES (INAMU) (2007). Política Nacional para la Igualdad y Equidad de Género (PIEG). (2007-2017). Resumen Ejecutivo. San José.

INSTITUTO NACIONAL DE LAS MUJERES (INAMU) (2008). Indicadores/trabajo remunerado y género. Disponible en: http://www.inamu.go.cr/. Consultado: 11/04/08.

LERUSSI, R. (2008). Trabajadoras domésticas nicaragüenses en Costa Rica. En las encrucijadas de un debate feminista. Tesina Magister. Madrid: Universidad Complutense de Madrid.

MORENO-FONTES, G. (2002). Feminización de las migraciones. Disponible en: http://www.ilo.org/public/spanish/dialogue/actrav/publ/129/7.pdf . Consultado: 11/04/08.

PEREIRA DE MELO, H. (1993). "Feministas y empleadas domésticas en Río de Janeiro". En Chaney, E. y García, M. (Compiladoras): Muchacha / cachifa / criada / empleada / empregadinha / sirvienta / y... más nada. Trabajadoras domésticas en América Latina y El Caribe. Caracas: Nueva Sociedad. .

SAGOT, M. (2006). "La paz comienza en casa: Las luchas de las mujeres contra la violencia y la acción estatal en Costa Rica". En Lebon, N. \& Maier, E. (coordinadoras): De lo privado a lo público: 30 años de lucha ciudadana de las mujeres en América Latina. México: Siglo XXI; UNIFEM; LASA.

SANDOVAL, C. (2000) (compilador). ¿Cómo me siento en Costa Rica? Autobiografías de nicaragüenses. San José: Instituto de Investigaciones Sociales (UCR). 